\author{
Fátima Cecchetto \\ Instituto Oswaldo Cruz - Fiocruz
}

Simone Monteiro

Instituto Oswaldo Cruz - Fiocruz

\title{
Discriminação, cor e intervenção social entre jovens na cidade do Rio de Janeiro (RJ, Brasil): a perspectiva masculina
}

Resumo: Este trabalho aborda a temática da discriminação e do racismo entre jovenscariocas, ana lisando as percepções, vivências e reações do grupo diante das situa ções de preconc eito. O estudo integra uma pesquisa ma is a mpla sobre a repercussão de intervenções sociais nas trajetórias de rapazes e moças das camadas populares. Para tanto, foram rea lizadas entrevistas em profundidade com 42 jovens, entre 18 e 24 anos, com e sem a participação em projetos voltados para a formação da cidadania e capacitação profissional. No presente artigo foi privilegia da a análise das falas dos/das jovens sobre os circuitos, as redes e os processos que envolvem as práticas discriminatórias na cidade do Rio de J a neiro. Destacamosas configurações que a discriminação e o racismo assumem entre osjovens do sexo masculino com experiência em projetos sociaise sua simplic ações para a sociabilida de e o acesso a determina dos espaç os sociais. A perspectiva comparativa entre os/as jovens com e sem experiência institucional fornec eu pista sinteressantes sobre as interfaces entre raça, cla sse e gênero, a mpliando assim o entend imento das especificidades das rela ções racia is no Bra sil.

Palavras-chave: discriminação, juventude, intervenção social, relações raciais, gênero, masculinidade.

Copyright (c) 2006 by Revista Estudos Feministas

${ }^{1}$ Tendo em vista que existem diferentes acepções das categorias utiliza das na classific ação da corl raça, neste artigo os termos serão a presentadosem itálic 0 , ora referentes às obras citadas, ora às autoc lassific ações dos entrevista dos.
Desde os anos 1980 um conjunto de trabalhos sobre as desigualdades racia is no Brasil tem evidenciado o quanto indivíduos classifica dos como negros (pretos e pardos) ${ }^{1}$ estão expostos a desvantagens cumulativas ao longo de sua trajetória de vida. No escopo dessas investigações destacou-se o papel central que a filiação racial joga na transmissão intergeracional das desigual- 
${ }^{2}$ Ca rlos HASENBALG e Nelson do Valle SILVA, 1993; e HASENBALG, 1996.

${ }^{3}$ A produção acadêmica mencionada foidesenvolvida a partir dos dados dos censos demográfic ose daspesquisas domic ilia res rea liza das pelo Instituto Bra sileiro de Geografia e Estatística (IBGE) nos anos de 1976 e 1980 . O procedimento dos estudos consiste em estabelecer relações esta tísticas entre a cor declarada das pessoas entrevistadas e outras c a ra c terístic as soc ioe conômic as e demográficas destas mesmas pessoas (cf. HASENBALG, 1996, p. 239-241).

${ }^{4} \mathrm{Na}$ seleção dos quatro projetos foram contempla dos os seguintes critérios: a) inclusão de dois projetos desenvolvidosem comunidades de baixa renda; b) inclusão de dois projetos volta dos para o atendimento de jovensexmoradores de rua; c) possibilidade de fomento de parceria institucional, pela incorporação de projetos socia is desenvolvidos na Fundação Oswaldo Cruz; d) inclusão de pelo menos um projeto que abordasse a temática das relações raciais; e) acesso seguro às comunidades, devido à violência urbana nas favelas cariocas; f) perspectiva de comparação com o estudo de Simone MONTEIRO, 2002, desenvolvido com jovens da favela de Vigário Geral.

${ }^{5} \mathrm{O}$ termo intervenção social a qui se refere a osprogramasde capacitação profissional e educação para a cidadania, rea liza dos por instituições govema menta is e/ou orga niza ções da socieda de civil. Esses programas variam em termos de enfoque temático, tempo de duração, entre outros aspectos, conforme ilustra o trabalho de Regina NOVAES e Clara MAFRA, 1998.

${ }^{6}$ NOVAES, 1997; e Mary CASTRO, Miriam ABRAMOVAY e Maria das Graças RUA, 2001.

${ }^{7}$ NOVAES, 1997, p. 150. dades sociais. Isso foi comprovado pelas taxas menores de mobilida de ascendente para os indivíd uos negros, assim como pelos obstá culos ma iores enc ontra dos pelas fa mílias chefiadas por pessoas de cor negra - mesmo as pertencentes aos extratos socia is médios e altos - para transmitirem o status alcançado a seus filhos. ${ }^{2}$ Seguindo esses achados, alguns estudos demonstra ram as disparida des em termos de corno acesso à educação e à saúde, na estratifica ção social e na estrutura ocupacional brasileira. ${ }^{3}$ Contudo, a relevância que a cor/raça adquire na sociabilidade cotidiana e nas diferentes formas de adoecimento ainda é pouco investigada na produção acadêmica nacional. Ademais, observa-se a escassez de pesquisa s qua lita tiva s sobre as percepções e experiências da discriminação racia I no Bra sil.

Nessa perspectiva, este artigo aborda as vivências da discriminação e do preconceito na visão de moças e rapazes das camadas popula res do Rio de J a neiro. Tem-se como propósito a nalisar os signific ados a tribuíd os às suas experiências. Para a tingir tal objetivo foram realiza das entrevistas em profundidade, focalizando o percurso escolar/profissional e a fetivo-sexual de 42 jovens entre 18 e 24 anos, com e sem partic ipação em quatro projetos socia is desenvolvidos na cidade do Rio de Janeiro. ${ }^{4}$ Vale destacar que o presente trabalho integra a pesquisa Sexualidade, gênero e população negra no Brasil e na Colômbia: a valiações qualitativas, a poiada pela Fundação Ford, cuja finalid ade é a valiaro impac to de intervenções soc ia is ${ }^{5}$ nas trajetórias de jovens das camadas populares.

o ponto de partida foram alguns estudos que analisaram a repercussão de intervenções socia is promovidas por organizações não-governamenta is no aumento das perspectivas de vida de jovens que vivem em áreas pobres ou de risc $0 .{ }^{6}$ As investigações revela ram que os "jovens de projeto"7 apresentavam maior capital simbólic 0 , tra duzid o pela postura assertiva e uma linguagem mais ampliada sobre os direitos socia is, em comparação a os seus pares do mesmo círc ulo social sem essa vivência. Nesse sentido, a perspectiva de mediação e ampliação das redes sociais, que caracteriza as ações dos projetos sociais, constituiu-se o marco interp retativo deste a rtigo, orientando a presente análise sobre as configurações que a discriminação e o preconceito racial adquiriram em um segmento juvenil específico.

O trabalho está dividido em três partes. Na primeira, refletimos sobre a temática das relações raciais na sociedade brasileira, por meio de um breve mapeamento da literatura nacional. Na segunda parte, apresentamos uma caracterização sociodemográfica dos entrevistados 
${ }^{8}$ C leusa TURRA e Gusta vo VENTURI, 1995; Lílian SCHWARCZ, 1996; Kabengele MUNANGA, 1996; Ĺvio SANSONE, 2003; e Luiz OLVEIRA e Paula Cristina BARRETO, 2003.

${ }^{9} \mathrm{Na}$ literatura acadêmica consultada, preconceito e discriminação racial, em geral, não são diferenciados. Neste trabalho optamos por seguir esse padrão. Todavia, existem especific ações conceituais que configuram distintas maneiras de abordaro tema das desigualdades raciais. No verbete do Dicionário de Ciências Sociais, preconceito é definido como "uma atitude negativa, desfa vorável para com um grupo ou seus componentes individua is [...] com ênfase em grupos étnicos". No mesmo dicionário, a discrimina ção "denota tra ta mento desfa vorá vel da do a rbitra ria mente a certas categorias de pessoas [...] as práticas podem incluir a segregação [...] e expressõesconcretas em que se encama o preconceito" (FGV, 1986). A compreensão de que discriminação envolve necessariamente uma a ção concreta tem sido a dota da por a lgumas orga niza ções nãogovemamentais de defesa dos direitose da cidadania, tendo por base documentos oficia is que indicam as sanções que devem ser aplicadas nos casos em que oc orreu discrimina ção. Ver http:// www.dhnet.org.br/w3/ceddhc/ bda dos/c a rtilha 14.htm, a cessa do em 20 de março de 2006.

${ }^{10}$ Ver G ilberto FREYRE, 1984.

${ }^{11}$ O Projeto UNESCO de Relações Raciais, cujo propósito era documentar, compreender e disseminarpara o mundo (pós-genocídio na zista) a suposta fórmula da democracia racial brasileira. As pesquisa sforam rea liza das no Rio de Janeiro, São Paulo, Bahia e Pemambuco e contaram com a participação de sociólogos e antropólogos, entre os quais Luiz de Aguiar Costa Pinto, Florestan Femandes, Roger Bastide, Thales de Azevedo, Oracy Nogueira, Charles Wagley, René Ribeiro e Marvin Harris. Sobre a história do Projeto UNESCO de Relações Raciais, ver Marcos MAIO, 1997. e os resultados gera is relacionados às várias dimensões da vivência da discriminação do grupo em questão. Na terceira, focaliza mos os rela tos sobre as situações vividas por rapazes com experiências em projetos socia is.

\section{Articulando discriminação e classificação de cor/raça}

As pesquisas sobre preconceito racial entre os habitantes das cidades brasileiras norma Imente revela $\mathrm{m} o$ descompasso entre a visão dos indivíduos acerca da sociedade, onde se reconhece a existência do racismo, e a autopercepção do preconceito, na qual as pessoas afirmam não ter atitudes racistas. ${ }^{8}$ Ainda de acordo com essas reflexões, a identifica ção do ra cismo no outro revela uma dimensão peculiar das relações racia is no país. Nessa direção, dema is trabalhos busca ram desvendar não só os mecanismos e círculos viciosos da discriminação e do

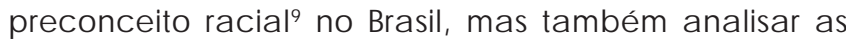
especificidades, tanto do ponto de vista crítico quanto de sua positivação.

Vale lembrar que as imagens sobre a originalidade do padrão racial brasileiro vêm de longa data, ${ }^{10}$ mas ganharam grande visibilidade com as pesquisas patroc inadas pela UNESC O nos a nos $1950 .{ }^{11}$ Os trabalhos constataram a forte associação entre cor/raça e status socioeconômico, e a ampla documentação produzida confirmou a presença de preconceitos e discriminação racial em todas as esferas. Contudo, os resultados das investigações revelaram a tensão ainda presente entre 0 mito da democracia racial e o racismo à brasileira. ${ }^{12} \mathrm{Ma}$ is recentemente, a partir de iniciativas ocorridas durante a gestão de Fernando Henrique Cardoso (1994-2002), programas govema menta is de a ção a fima tiva com recorte racial vêm sendo implementados no país, dinamizando o debate público em tomo do combate às desigualdades racia is. ${ }^{13}$

Dentre as discussões sobre as particularidades das rela ções ra cia is no Bra sil, considera mos releva nte desta car o sistema de classificação cor/raça. Como vários estudos a testam, a concepção da discriminação racial no cenário brasileiro entrelaça-se com as discussões sobre as ca rac terístic a s físic a s a tribuíd a sà "raça". Isso signific a dizer que a aparência (fenótipo) é um critério central para a classificação de cor. O trabalho clássico de Oracy Nogueira, ${ }^{14}$ por exemplo, mostrou como o modo de classific ação da cor de um indivíduo no Brasil é um procedimento que inclui várias combinações. Ao fenótipo misturam-se outros princípios demarcatórios, a saber, a 
12 MAIO, 1999

13 Ver Antônio GUIMARÃES, 1999; PeterFRY, 2000; Rosa ne HERINGER, 2001; MAIO e MONTEIRO, 2005.

${ }^{14}$ Ver NOGUEIRA, 1998, p. 199243.

15 Ver FRY, 1991.

${ }^{16}$ Ver MAGGIE, 1996.

${ }^{17}$ Ver SANSONE, 2003, p. 80.

${ }^{18}$ Ver Sérgio ADORNO, 1996, p. 256; Antônio GUIMARÃES, 1997, p. 68; e Sílvia RAMOS e Leonarda MUSUMECI, 2005. classe social, a educa ção e os a tributos corpora is como postura, modo de vestir, a lém do cabelo, existindo, to da via, uma correlação estreita entre o grau de escuridão da pele e o preconceito e a discriminação sofrida. Esse componente do padrão racial brasileiro, calcado na aparência ou "marca", distingue-se do preconceito de "origem", característic o de outras socieda des, entre elas a norte-americana, que reúne na mesma e única categoria negros e mestiços por ma is brancos que eles sejam fenotipic amente.

Autores como Peter Fry ${ }^{15}$ e Ivonne Maggie ${ }^{16}$ contribuem para pensar esse tema ao desenvolverem, cada um a seu modo, análises sobre a existência e articulação de variados modos de classificação racial, qua is seja m: o modo dic otômico ou bipolar (negro/branco), o modo censitá rio (preto/branco/pardo/a ma relo/indígena) e o modo múltiplo. Este último, a mplamente utiliza do pela popula ção, caracteriza-se por um contínuo de gradações expressas em uma nomenclatura variada, incluindo mulatos, morenos, escuro, claro, etc. Para Maggie, o gradiente "escuro-claro" fala da suposta naturalidade e dilui a s op osições por ser rela ciona l, porém va loriza os ma is cla ros e constrange os ma is esc uros. $O$ trabalho de Fry, por sua vez, positiva a especificidade de uma miríade de cla ssific ações, vistas como categorias nativas, o que possibilita o conta to de pessoas de várias cores diferentes.

Ĺvio Sansone, ${ }^{17}$ em pesquisa sobre o surgimento de uma nova terminologia da corem duas cidades da Bahia, examina os conta tos inter-racia is loca is, caracterizando os espaços onde a cor adquire maior ou menor importância para orientar as relações socia is e de poder. O que essa pesquisa etnográfica traz à tona é a existência de uma hierarquia de domínios e espaços, que ele designa como áreas leves e áreas pesadas para as relações raciais. 0 mercado de trabalho, o merca do matrimoniale da paquera e os conta tos com a polícia seriam exemplos de áreas em que a corfunciona como empecilho. Algunsambientes de lazer, incluind o a Igreja Ca tólic a, a pa recem como espaços onde existe o mínimo de preconceito e discriminação.

0 processo específico de discriminação baseada na cor da pele, repercutindo na violação dos direitos da cidadania, tem sido descrito por alguns cientistas socia is brasileiros, embora admitam que as investigações ainda sejam incipientes no pa ís. ${ }^{18}$ Sérgio Adomo, em estudo sobre a polícia e o sistema penal na cidade de São Paulo, comprovou a ocorrência de um tratamento discrepante em matéria de direitos humanos para os cidadãos negros. Sua conclusão é que o racismo é um critério importante na definição das práticas policia is e penais. Faz parte, a inda, 
${ }^{19}$ Ver Luiz Edua rdo SOARES et al., 1996; e Alba ZALUAR, 1999 e 2004, entre outros.

20 Os autores indicam que os brancos constituem $54 \%$ da população do Brasil, massomente $45,1 \%$ das vítimas de homicídio naquele ano. Já os pardos são $39,5 \%$ da população, mas $44,5 \%$ das vítima s; e os pretos sã o $5,7 \%$ da população e $9,7 \%$ das vítimas, o que revela um risco maior de homicídio para os pretos e pardos. Ver CANO e FERREIRA, 2003, p. 281-316.

${ }^{21}$ Maria Cecília MINAYO, 1994.

${ }^{22}$ Cabe pontuarque a produção biomédica internacional com recorte racial, sobretudo a norteamericana, é consistente e tem apresentado diversos questionamentos, de ordem teóricometodológica, relevantespara as investigações acerca dessa temática. Ver MONTEIRO, 2004. ${ }^{23} \mathrm{C}$. MAIO e MONTEIRO, 2005.

${ }^{24}$ Ver STOLC KE, 1991.

${ }^{25}$ VerCRESHAW, 2002, p. 174-176. desse padrão discriminatório o crescimento das mortes prematuras de jovens negros por homicídios em decorrência da rivalidade violenta das quadrilhas de traficantes de drogas, e entre estas e a polícia, fenômeno típico das áreas metropolitanas, em particular no Rio de Janeiro. ${ }^{19}$

O impacto do viés racial na vitimização da população negra foi analisado por Inácio Cano e Carlos Eugênio Ferreira. Baseados na Pesquisa Nacional por Amostra gem de Domic ílios (PNAD) $1998,{ }^{20}$ os pesquisa dores assinalaram a possibilidade de uma coorte de homens negros não chegar a idades avançadas por causa do homicídio, causando um agravamento do já constata do quadro de desequilíbrio populacional entre os sexos. Segundo os a utores, a expectativa de vida desse grupo no Rio de Janeiro (63,6 anos) é inferior à do Brasil, mas seria ma ior se nã o houvesse homic íd ios, provand o que o impac to das mortes violentas no Rio de Janeiro é mais intenso do que a média brasileira.

O dramático quadro do aumento da mortalidade por homicídio de jovens negros no Brasil tem chamado a atenção de demógrafos e epidemiologistas, sendo considera do a tualmente um grave problema de saúde pública. ${ }^{21}$ Ainda no campo da saúde, faz-se necessário ressaltar que a produção acadêmica biomédica focada nas interfaces entre raça e saúde a inda é tímida no contexto brasileiro, não havendo estudos sobre as conseqüências da discriminação racial nos a gravos a saúde. ${ }^{22}$ Nos últimosanos, esse cená rio vem se modific ando em decorrência do interesse de pesquisadores do campo da saúde coletiva e de políticas públicas volta das para a "saúde da população negra", conforme análise de Maio e Monteiro. ${ }^{23}$

Outra perspectiva que ajuda a entender a trama da discriminação racial é a da interseccionalidade. Em estudo pioneiro, a antropóloga Verena Stolcke ${ }^{24}$ frisou a necessidade de se examinar o modo como as diferenças "sexua is" e "raciais", a lia das à s da de classe, a rtic ula m-se para reproduzir a opressã o na socieda de ca pitalista, tendo por base a naturalização das desigualdades socia is. Kimberlé Crenshaw, ${ }^{25}$ em outro contexto de pesquisa, mostrou que freqüentemente o racismo, a dominação masculina, a pobreza e outros sistemas discrimina tórios se cruzam, estruturando as posições rela tivas dos indivíduos, segundo o gênero. A perspectiva indicada pelas autoras nos parece fundamental para pensar os diversos a rranjos a tra vés dos qua is as formas específic as de discriminação se manifestam no plano da sociabilidade do grupo pesquisa do. 
Com essas referências em mente, a presenta remos, na segunda parte deste artigo, um breve perfil dos 42 jovens, de ambos os sexos, com e sem experiência em projetos sociais, focalizando os depoimentos sobre as experiência s de discrimina ção. Cabe assinalarque o olhar conferid o a o tema privilegiou os sistemas de representações e práticas sociais do universo selecionado, dentro da tradição socioantropológica, a través de descrições e interpretações dos valores e práticas de grupos socia is demarcados. Para facilitar a leitura, os jovens com participação em projetos socia is serão doravante denominados de "P" e os sem experiência de "NP".

\section{Vivências da discriminação entre jovens cariocas}

Dos 42 entrevistados, 24 tinham participado de projetos socia is e 18 não tinham tido essa experiência, mas a mbos os grupos a presenta va $\mathrm{m}$ c a ra c teństic as semelha ntes em relação a sexo, idade, inserção social e local de moradia. Todos já freqüentaram a escola, mas apenas meta de continua a estudar. Comparativamente, os jovens NP revela m menorescolarida de, a pesa rdas diferenças não serem exp ressivas.

Em relação às suas famílias de origem, verific ou-se que a maioria é da Região Sudeste. Os/as jovens são mora dores de fa velas e/ou ba irros popula res (Vigá rio Geral, Santa Cruz, Maré, Vila do Pinheiro e em situação de rua). A grande parte vive nesses locais desde seu nascimento, o que indica a permanência desse grupo com suas famílias de origem. Em relação à conjugalidade, cerca da metade decla rou-se solteiro/a. Apenas dez jovens a firmam manter uma união estável.

Dos 42 jovens entrevistados, em torno de $50 \%$ declarou estar trabalhando. Desses, a maior parte havia participado dos projetos socia is e estava exercendo a tivida des vincula das ao setor cultural (monitores, locução, perc ussão, a tor) ou o cupa do sno setor de serviç os (fa mác ias, supermerc ados, confecções). Compa rativa mente, os jovens

${ }^{26}$ A noção de "desafiliação social" é utilizada por Robert Castel para elucidaros processos sociais que culminaram em situações de desproteção social e desvinculação das redes próximas. Em contraposição a o conceito de exclusão, "desa filiação" fala de sujeitos ativos, participando das lutas sociais e não somente de uma subjugação à lógica econômica (CASTEL, 1995). sem experiência em projetos estavam ma is representados no setor informal e precarizado do mercado de trabalho (ambulante, pedreiro, catador de lixo, biscateiro) ou desempregados. O desemprego é expressivo entre as mulheres NP, segmento possivelmente ma is afetado pelas rápidas transforma ções no mundo do trabalho, situa ção já apontada nos estudos sobre o processo de "desafiliação social"26 nas socieda des contemporâneas.

Cabe observarque, nos dados de que dispomos, a maioria dos/das jovens $P$ se percebe vivenciando uma 
situação social e econômica melhor que a de seus pais, quando eles tinham a mesma idade. As principais evidências diziam respeito à menor quantidade de filhos, à a quisição de bens ma teria is, às melhores condições de moradia e a o distancia mento do local de origem. Na visão dos rapazes e moças NP, entretanto, seus pais levavam a vida em situação mais favorável, com destaque para a ausência do desemprego ("tinham ma is oportunidades") e da violência urbana ("naquela época não tinha tráfico").

As informações relativas à cor/raça revelam que na autoc lassific ação - feita a partir da pergunta aberta Qual a sua cor ou raça? - 18 jovens se declararam como "negros", 8 "pardos", 6 "morenos", 4 "pretos" e 4 "brancos". Um não respondeu, outra deu uma resposta ambivalente ("morena-preta"), e "pretinha" apareceu uma vez. Grosso modo, não existe diferença de cor significativa entre os entrevista dos com e sem partic ipação nos projetos. A menor proporção de brancos no universo analisado é coerente com as estatístic as naciona is sobre a maior concentração de pretos e pardos nos extratos populaciona is de menor poder a quisitivo.

Além da pouca variação na terminologia da corl raça, nos chamou a a tenção a maiorrecorrência do termo negro entre os jovens que integraram os projetos e o uso da categoria preto apenas por aqueles sem a referida inserção. Tal fato, possivelmente, deve-se à mudança do sinal de valor do termo negro, que perdeu a conotação ofensiva, transformando-se em um símbolo de modemidade entre os jovens, conforme já constatado por Sansone em pesquisas no Rio e em Salvador. ${ }^{27}$ Ademais, dado que o modo como as pessoas indic am a própria coré o resulta do de uma combinação de fatores como nível educacional, renda e faixa etária, estilo, entre outros, podemos supor que a vivência no projeto seja igualmente importante na incorporação de uma taxonomia da cor/raça dos movimentos socia is, que tem privilegia do a categ oria racial negro. Isso nã o significa a firmar que o modelo bipolar de classific a çã o foi a dotado pelo grupo pesquisado, uma vez que permanece o uso da categoria pardo.

Para um aprofundamento da repercussão dos projetos na afirmação de uma identidade racial e nas relações inter-racia is, dentre outros temas, ca beria a rtic ular os dados relativos à discriminação com a análise da biografia dos jovense dasações promovidas pelos projetos. Aqui, privilegiou-se a discussão da temática racial a partir da experiência da disc riminação, segundo os entrevistados, recorrente em alguns contextos. Esse foco teve por base as perguntas relativas: 1) à percepção e contexto da discriminação; 2) a reações em face das situações de 
discriminação; 3) a op iniões a cerca das oportunidades no mercado de trabalho segundo gênero, cor e classe; 4) a visões sobre a implantação do sistema de cotas nas universida des brasileiras e o racismo.

Quanto às vivências $d a$ discriminação, não observa mos uma generalização. Do total de entrevistados, 20 homens e 10 mulheres referira $m$ ter vivid o a lgum tipo de discriminação. Dentre os casos mencionados, prevalece a discriminação por cor e local de moradia, seguido do que foi designa do como a parência pelos jovens, que inclui "modo de vestir", "condição social" e "deficiência física". As respostas não foram excludentes, isto é, a maioria descreveu a vivência de múltiplas discriminações. Dos entrevista dos que cita ram a discriminação porcor, meta de também mencionou aparência. Tais dados, a princípio, sugerem que, para os entrevista dos, a classe, expressa pelo modo de vestir e pela localidade, tem um peso mais expressivo que a cor na percepção das situações de discriminação, mesmo entre os autodeclarados negros e pretos. Aqueles que viveram nas ruas tendem a perder 0 vínculo com o lugar de origem, atenuando a importância da loca lidade na s configurações da discriminação.

Os dados sobre a importância da aparência no desencadeamento das práticas discriminatórias correspondem ao já mencionado padrão classifica tório brasileiro, ressalta do por Oracy Nogueira. Quer dizer, nas explicações sobre o preconceito no Brasil a cor não é o critério determinante, uma vez que a postura corporal, "o jeito", o vestuário e o contexto são percebidos como elementos igualmente relevantes.

Em relação a os contextosda discriminação, a maioria indic ou espa ços públic os, como shopping centers, a gências bancánias, ruas e restaurantes. Nesses loca is o preconceito se traduz pelo distanciamento dos transeuntes, descaso no atendimento, perseguição e violência dos seguranças dos esta belecimentos comercia is, assim como da própria polícia. Os depoentes atribuem o desencadeamento de atitudes discrimina tórias tanto pela condição social quanto pela cor. Depois do espaço público, o mercado de trabalho é identificado como uma área dura para a cor. Quando perguntados sobre a existência de oportunidades iguais no mercado, a maioria dos/das entrevistados/as reconhece a desigualdade entre homens e mulheres, pretos, pardos e brancos e pobres e ricos. No entanto, alguns percebem a diminuição da assimetria de gênero, pela conquista das mulheres nesse espaço. No que diz respeito à desigualdade entre ricos e pobres, destaca-se a ênfase da falta de escola ridade ("estudo") dos "pobres" na deteminação das oportunidades. 
No caso da assimetria entre pessoas de cores diferentes no mercado de trabalho, as falas apontam para a existência do preconceito contra pretos/negros, em contraposição a uma posição privilegiada dos brancos. Parte não explicita os motivos; outros se referem à a usência de negros/pretos em espaços como a mídia eletrônica, à condição social ou à aparência para justificar o menor acesso dos negros a mercado. O legado histórico de desvantagensacumula das pela população negra ta mbém é citado, assim como situa ções de racismo no cotidiano, em contextos diversos. Todavia, a Iguns destacam muda nça s positivas em termos da diminuição do racismo. No geral, os achados assinalam a percepção das desigualdades racia is nas oportunidades no mercado de trabalho. No entanto, as explic ações são va riadas e não se restringem à cor, demonstrando como cor e classe mantêm entre si uma estreita dialética.

Em relação a os sentimentos e reações em face da discriminação, prevaleceu o que denominamos de interiorização negativa indicada pelas falas sobre sentimentos de humilhação, constrang imento, tristeza e malestar. Alguns depoentes a legaram ter reagido com ironia, silêncio e/ou indiferença ("Não me deixo levar"; "Eu não senti nada"; "Levarna brincadeira e na sa canagem") como estratégia para atenuar o preconceito sofrido. Os casos de extema liza ção, isto é, a explic ita ção de a lguma reação, foram poucos, sendo manifestos pela demonstração de raiva, xing a mentos e ag ressão física.

Observamos que a discrimina ção a inda é vivida de modo bastante individualizado, não havendo referências a o contexto institucional ma is a mplo ou busca a entida des de defesa da cidadania ou a redes socia is de proteção, como organizações do movimento negro. Colabora com esse ponto de vista a constatação de que no universo analisa do apenas dois jovens formalizaram queixa na polícia nos casos de discriminação racial. Desse modo, os dados indicam que cor e local de moradia são aspectos de discriminação mais recorrentes, e que existem sobreposições entre ta is discriminações, revelando as interfaces entre cor, território e classe social/status.

Em relação ao sistema de cotas para negros, metade dos/das entrevistados/as já ouviu falar, havendo um predomínio dos homens com participação em projeto. Tal dado sugere uma certa visibilidade desse assunto entre o grupo, embora as explic ações, em geral, indiquem uma dificuldade de compreensão do tema. Quanto à opinião dos rapazes e moças acerca dessa proposta, prevalecem os p osic iona mentos desfa vorá veis ou crític os. Eles a legam, incluindo vários a uto-identificados negros, que os direitos 
${ }^{28}$ Ver Mala HTUN, 2004; e Mônic a GRIN, 2004. são iguais e que esse processo desqualifica os supostos beneficiados. Um depoente ilustra essa visão:

Eu como negro deveria apoiarisso. Se todo mundo é ser humano, tem direitos iguais, todos têm a mesma possibilidade, porque para negro tem que existir uma cota? Por quê? O negro é menos competente? Quem vai para as universidades públicas? Aquelas centenas de donos daqueles carros que estão lá. Um cara que veio da favela não tem um carro. É muito complicado, deveria $m$ existir direitos igua is para todos. Tanto para 0 negro, como o branco, o gordo, o cego, o surdo, como o cara que está na cadeira de rodas. Não cota para um certo grupo.

Poderíamos dizer que os jovens com posicionamentos desfavorá veis defendem princípios universa listas e temem o a cirramento do preconceito ra cial. Em contraposição, a queles que argumentam a favor das cotas assinalam a dificuldade de acesso da população negra e/ou de classe média baixa a o ensino de qualidade, reconhecendo a necessidade de tratamento específico para esses grupos sociais, o que é expresso na seguinte avaliação de um outro rapaz negro:

Eu acho interessante. Porque é diferente o estudo da pessoa negra, da favela do que do rico, que tem escola particular, escola boa mesmo. Escola pública é boa, masnão é tão assim. Há diferenças de estudo, entendeu [...] eu acho que tem que ter reserva para negros e pobres. Muitos não têm cond ições de pagar, e a escola pública o ensino é fraco.

Vale notara existência de opiniõesambiva lentes que a firma $m$ tanto o benefíc io individual das cotas, no sentido da a mpliação de oportunidades educaciona is, qua nto as suas implicações negativas, como a desqualificação pessoal e o não-investimento na melhoria do ensino público. Os a chados convergem com a s controvérsia sa tua is a cerca das políticas de cotas, conforme indicam algumas a nálises. ${ }^{28}$

Por fim, ressalta mos que nas opiniões sobre a existência do racismo no Brasil existe um alto reconhecimento de sua presença entre os/as entrevistados/as, em conformidade com estudos nesse campo.

\section{As discriminações em falas masculinas}

$\mathrm{Na}$ análise dos discursos dos/das 30 jovens que a legaram ter vivido discriminação chamam a atenção 0 predomínio de falas masculinas (20) e a recorrência de depoimentos de discrimina ção por cor e a parência entre a queles com experiência instituc ional. Tal configuração nos 
fez optar por uma análise ma is sistemática do material de 12 rapazes que integraram os projetos. Essa escolha mostrou-se importante porque nos pareceu o primeiro passo para entender as interfaces entre raça e gênero e seus matizes. Desse modo, passamos para a análise dos discursos sobre a discriminação a partir da perspectiva masculina .

\section{Discriminação: contextos e reações}

Em relação à vivência da discriminação em espaços públic os (shopping center; a gência bancária, entre outros), há depoimentos sobre perseguição e agressão por parte de seguranças dos estabelecimentos. No universo analisado apenas um rapaz negro reagiu ativamente, chamando a polícia e formalizando uma queixa contra o agressor:

[...] quando eu fui saindo da loja um segurança me abordou, me jogou na parede. Me virei, saí de perto dele e falei: "O que está acontecendo?" Ele falou: "Eu sou policial e você está preso". Eu falei: "Estou preso porquê? Sei meus direitos. Se você é policial, não está fardado, tem que se identificar. Se você não se identificar, para mim você não é policial".

Se, por um lado, homens jovens negros e pobres, em geral, são mais vigiados e perseguidos nos espaços públicos, por outro, é raro haver qualquer tipo de enfrentamento, o que decorre, muitas vezes, da crença de que seus direitos não serão garantidos perante as autoridades policiais. São dignos de nota os dados da pesquisa de Ramos e Musumeci sobre a abordagem policiale discriminação no Rio de Janeiro, em que a maior parte dos jovens de corpreta afirma ter sofrido ameaça ou

${ }^{29}$ Ver RAMOS e MUSUMECI, 2005, p. 118. intimidação no conta to com a polícia..$^{29} \mathrm{~A}$ fala do próprio personagem dessa história ilustra essa vulnerabilidade, ao mesmo tempo que demonstra a ruptura com o silêncio diante da opressão:

[eu falei] "você está pensando que eu sou trouxa, eu moro em comunidade, em Vigário Geral. Tá pensando que eu não conheço essas coisas! Vocês querem dar porrada e dizer que eu quero roubar o shopping". E detalhe, eu estava muito bem a mumado. O que não justifica, porque é o direito de todos de ir e vir, sem problema. Eu estava trajado, sapa to, calça social, todo direitinho. Simplesmente desci, chamei a polícia. Tem uma cabine policialali... fomospara a delegacia para poder abrir um inquérito contra o cara.

Esse relato exprime uma possível correlação entre as ações educ a tivas dos projetose a concepção de direitos 
socia is dos jovens a tendidos. Essa pista será explora da em a nálises subseqüentes sobre os fundamentos e a tividades promovida s pela sintervenç ões soc ia is. Ressa lta mos, a inda, que o jovem acima qualific a como racismo a atitude do segurança caracteriza do porele como branco. No entanto, comentando o episódio, não a tribuiu somente a os brancos tal comportamento. De modo enfático, salientou os atos discriminatórios dos negros, demarcando uma postura de distanciamento do discurso da pola rização racial.

Eu acho que ele fez por racismo. O cara era branco. Não por ele ser branco, tem negro também que é racista. Tem nego que é negro, não gosta de assumir que é negro e não gosta de negro, eu conheço pessoas assim ta mbém.

Ainda no espaço público outro rapaz negro a firma ter sido injustamente impedido de entrar em uma agência bancária: a porta automática o barrava. Percebeu, no entanto, que tratamento igual não fora dispensado a um "cara branco de temo e mais cinco pessoas [...]". Embora reconheça o racismo, esse rapaz também mencionou o constrangimento em ser percebido como objeto de insegurança e medo pelo simples modo de vestir: "Muitos a cham que assa ltante são a queles que estão mal vestidos". A fluidez na explicação sobre um tratamento diferenciado para negros e pobres em determinados espaços sociais é assinala da na fala de muitos entrevistadosautoclassific ados como negros, pardos ou brancos. Eles lamentam os preconceitos dirig idos às pessoas de classe social ba ixa, 0 que é traduzido pela indiferença ou descaso dos vendedores/comerciantes para com eles. A discrepância no atendimento devido à classe foi comentada por um rapaz branco:

Eu lembro como se fosse hoje, ficou marcado [...] eu entrei na loja, a pesarde estar com a minha madrinha, eu era bem jovem, acho que eu estava com 16 anos ainda, entrei no shopping com ela, uma certa discriminação, a pessoa não quereratender ela direito.

Já no ambiente de trabalho, um jovem autoc lassific ado negro reparou que existiam expectativas particulares nesse circuito, a través de olhares dirigidos a ele que sinalizavam uma censura sobre o seu modo de vestir. Nesse sentido, o entrevistado dá um significado específico a sua vivência:

[...] não acredito que isso tenha sido uma forma de disc rimina ção, mas uma forma de orientação quando eu fui promovido para auxiliar de representação e vendas da editora. Onde iria ter stand em Bienal 
[congresso], falaram que eu tinha que ir bem vestido. Aí eu pensei comigo: "Como eu posso ir bem vestid o se não tenho dinheiro para comprar boas roupas?" Isso era uma forma de discriminação, mas era uma pessoa que dizia. Foi que daí eu vi que essa pessoa tinha discriminação, foi quando o chefe me doou as roupas dele. Aí eu passei a andar bem vestido. Não sei, eu acredito que tenha sido mais uma orientação, [...] queria dizer que, se eu estivesse mal vestido naquele lugar, eu poderia estar não a traindo cliente. Tem que ter uma boa imagem...

Esse depoimento tem muito a dizer sobre o peso da condição econômica, traduzida pela aparência, nas explicações das situa ções de discriminação vividas pelos entrevistados. A falta de ênfase explícita no preconceito racial esteve presente na fala de mais um jovem negro, que decretou em tom incisivo: "o mais importante é ter dinheiro no bolso". O que fica dessa afirmação é a visão de que a discriminação racial tende a ser suplantada pela riqueza. Como tal, remete a algumas discussões teóricas sobre o modo como cor, classe e sta tus estão relacionados no Brasil em várias situações de interação social. Isso corrobora o aspecto situacional da discriminação racial entre os pesquisados, dada à importância que outros critérios soc ia is têm nos processos de diferencia ção social. Todavia, a indistinção entre raça e classe não se confirma, porexemplo, no acesso a o merc ado de trabalho, conforme comenta um rapaz branco:

Eu acho que para os negros existe muito racismo no mercado de trabalho. Preconceito pela raça da pessoa mesmo. Às vezes a pessoa é a té bem educada, se expressa bem, mas não tem chance.

Outro rapaz negro vai nessa mesma direção ao afirmar o preconceito de cor distinto do de classe:

$\mathrm{Na}$ questão desses empregos que eles pedem perfil, a cho que para brancos é mais fácil. Eu tenho amigos que já foram dar entrevistas, por telefone eles ligam e dizem: "Gostamos muito do seu currículo, muito bom, tem tudo que a gente quer dessa pessoa". Aí pergunta qual a cor, no cumíc ulo a gente não põe, aí quando diz que é negro, é moreno, aí diz assim: "Ah, não, desculpa, vi errado".

O a mbiente midiático também aparece como um contexto responsável pela perpetuação de barreiras na mobilida de social dos negros. Dois comentá rios a ssinala ram a ausência de homense mulheres pretose "de cabelo ruim" nos programas televisivos, frizando a presença do racismo na sinstituições soc ia is. Entretanto, foi observa do entre a lguns 
o desloca mento do ra cismo ma is generaliza do na soc ieda de para uma dimensão ma is psicológic a e individual, conforme comenta um entrevista do auto definid o como pardo:

Acho que isso é coisa da pessoa mesmo. Por exemplo, o negro virar e dizer, ah, porque sou negro e tal. Eu acho que ele mesmo põe na cabeça dele. Já é dele, não tem isso. Hoje não tem.

A diminuição do preconceito foi notada por uma parte dos jovens, dentre os qua is a queles que tivera $\mathrm{m}$ ma is oportunidades de mobilidade e de circulação social decorrente da inserção nos projetos sociais. Chama a atenção que um depoente relate, com humor, a internalização de uma a valiação "negativa" de seu caso, pois acredita ser possuidor de uma marca distintiva que favorece a exclusão:

Sei lá, acho que eles veriam mais para o lado do branco..., agora também diminui um pouco aqui no Brasil, ninguém está ma is jog ando por esse la do aí, mas existe a inda sim. Porexemplo, uma empresa grandona, se tu chegar lá vai conseguir, eu com essa cara de bandido [balançou negativa mente a cabeça ]...

Tendo em vista que esse jovem conseguiu se inserir de forma bem-sucedida no mercado cultural, pode-se dizer que a vivência institucional concorra para atenuar os obstáculos para a ascensão social da população negra e pobre. Nessa direção, esse relato estimula uma reflexão sobre os processos específicos que marcam a experiência da discriminação entre os jovens pesquisados. A consta ta ção da perma nência do ra c ismo em detemina dos espaç os soc ia is, inc luind o possibilida des de preterição, não elimina o reconhecimento da diminuição do preconceito. Isso poderia indicar vivências simultâneas e variadas de processos de inserção social (promovida muitas vezes pelas ações dos projetos) e de barreiras sociais (limites na ascensão social).

Nessa direção, a maioria dos rapazes vivencia múltip la s disc rimina ções decorrentes da intera ção entre cor e classe social. A "identida de" territorial, definida a qui pelos laços sociais e simbólicos estabelecidos com áreas geográficas, ta mbém integra esse processo, como veremos a seguir.

\section{Temitorialidade e cor}

Parte dos rapazes entrevista dos a lega experimentar consta ntes tensões em função de estig mas a sso cia dosa os seus locais de moradia. A fala abaixo mostra a reação de um jovem, autodeclarado moreno, diante de uma 
apreciação negativa de sua condição de morador da Favela da Maré:

Minha amiga falou, você vai falarque mora na Maré? Vou falar que moro aonde? Na Barra da Tijuca, se eu moro na Maré? Se eu tenho que divulgaro meu projeto aqui, a minha grande oportunidade com pessoas, ONGs da França, Espanha, Peru, Paraguai, Uruguai. Eu tendo a minha oportunidade eu vou falarque moro na Barra. Não, eu moro na Maré e me orgulho disso.

Ainda nesse sentido, um rapaz reagiu aos comentários preconceituosos sobre sua comunidade, valorizando a s altema tivas de lazer existentes, como baile e forró, freqüentados por pessoas do asfalto. Demais moradores de fa velasta mbém menciona ram o desconforto de verem o lugaronde moram recorrentemente associado à criminalidade e às guerras entre traficantes e policia is. Os depoentes a firmam que isso normalmente ocorre quando precisam dar o endereço em lojas ou para emprego, ou seja, a territorialidade, nesse caso, é considerada um fa tor restritivo. Vale a pena transc rever um depoimento de um outro jovem pardo a esse respeito.

[...] quando eu vou procuraremprego eu botava o meu endereço no curículo: "Ah, pode aguardar". Até hoje eu estou aguardando. "Ah, Vila do Pinheiro, troca de tiros, bandidos." Então quer dizer já começou a discriminação dali. Eu li uma reportagem que pessoas jovens que moram no Morro do Alemão, que mora na Cidade de Deus, não conseguem emprego pormorar ali. Será que só mora pessoa s ba rra ali dentro do Morro do Alemão? Tem pessoas boas. Só que a sociedade não vê o outro lado.

A postura desse entrevista do, assim como a de outros jovens moradores de favelas no Rio de Janeiro, distingue-se do que acontece na maioria dos casos de discriminação por cor. Em vez do constrangimento, eles positivam a identidade territorial, reforçando o vínculo afetivo com o lugar, não obstante a violência trazida pelo trá fico de drogas nessas á rea s nos últimos a nos e sua simplic a ções nos pla nos simbólic o polític o para a teia de sociabilida de juvenil.

\section{Considerações fina is}

Nesta investigação privilegiamos a sexperiências de jovens das camadas populares cariocas sobre a disc riminação, busc ando identificar os contextos dessa vivência, impactos nas trajetórias de vida e as formas de enfrentamento empregadas. Constatamos que as experiências não são a testadas pela totalida de do grupo pesquisado, sendo mais freqüentemente relatadas pelos 
${ }^{30}$ Ver ADORNO, 1996; SOARES et al., 1996; e RAMOS e MUSUMECI, 2005.

31 Nos anos 1990, o aumento considerável da violência e da criminalidade no Rio de Janeiro trazidas pelo tráfico ilegal de drogas passou a fazer parte do cotidiano dos moradores, o que tem contribuído para a generaliza ção dos sentimentos de medo e insegurança decorrentes da ausência de mudançasnaspolíticas de segurança pública na área da violência (ZALUAR, 1999). 32 Fátima CEC C HEITO, 2004. homens, princ ipa Imente a queles que integraram os projetos socia is. A escassez de depoimentos femininos assinala 0 peso da assimetria das relações de gênero na percepção do racismo, o que é traduzido pela invisibilidade do componente racial nas situações de discriminação vividas pelas mulheres.

Esse cenário estimula reflexões sobre as interfaces entre as hierarquias de raça, classe e gênero, particula rmente no contexto brasileiro em que a ma rc açã o da cor, como um domínio de discriminação, não é dissociada da condição social das pessoas. Porém, isso não significa dizer que a identificação do racismo fique sempre subsumida à condição econômica e que a cor não jogue um papel relevante na dinâmica dasopressões. As descrições dos jovens reafirmam dados da literatura, segundo os quais o mercado de trabalho e a circulação por locais públicos são contextos em que cor/raça interagem com as desvantagens socia is preexistentes, produzindo uma dimensão específica da discriminação. Nesse particular, é fundamental ter em mente o fato de que os homens negros e pobres moradores de áreas urba na s sã o ma is vulnerá veis à s prá tic as disc rimina tó ria se racistas, inclusive pelas instituições criadas para protegêlos, como a polícia. ${ }^{30}$

Na reflexão realiza da, o aspecto da classe interliga da ao local de moradia ta mbém foi percebido pelos informantes como elemento desenc a dea dor de atitudes discriminatórias. Salientamos que, diferentemente das situações de discriminação racial, as manifestações de preconceito ligadas ao local de moradia suscitaram reações de positivação do lugar entre os informantes. Quer dizer, a teritorialidade traduz-se em motivo de orgulho, sobretudo entre jovens das comunidades empobrecidas, dada a importância do temitório no sistema de classificação social no Rio de Janeiro. ${ }^{31}$ A localidade serve, portanto, como pa râmetro de outra s forma sde c la ssific ação, pa riticula rmente classe social e estilos juvenis. Entre os jovens, a valorização da territorialidade também pode ser vista pelo ângulo das gratific ações reais e simbólicas advindas de possuir uma identidade coletiva em um cenário conturbado pela violência urbana. Nesse sentido, o que parece contar entre esses homens entrevista dos é o sentimento de adesão a um grupo e a afimação de um repertório comum, dado pela classific ação temitorial, interligada a manejo de códigos de sociabilidade masculina. ${ }^{32}$

No que se refere às reações diante das práticas discriminatórias, notam-se ainda posionamentos ma is assertivos e apoiados em concepções de direitos socia is entre os rapazes com experiência institucional. Tendo em 
${ }^{33}$ MONTEIRO e CECCHETTO, 2006. vista demais indicações sobre o impacto dos projetos na mobilidade social e profissionalização dos jovens, ${ }^{33}$ podemos suporque a experiência instituc ional conferiu uma distinção a os seus partíc ipes, se compa ra dos a os seus pares sem inserção nos projetos. Resta saber em que medida dema is diferenciações, como o predomínio da terminologia negro, podem ser atribuídas aos discursos e atividades promovidas no âmbito dos projetos sociais.

Com base nos depoimentos a na lisa dos, concluímos que os entrevistados estão posicionados em um espaço onde as manifestações de discriminação de cor/raça, classe e local de moradia se encontram, produzindo processos simultâneos e variados, porém, às vezes, danosos. Foi possível depreender que o racismo não age com igual força entre os jovens pesquisados, ou seja, há que se considerar a heterogeneidade das vivências da discriminação, evitando generalizações em demasia. A perspectiva comparativa entre os jovens com e sem experiência institucional, com recorte de gênero, adotada no presente texto forneceu pistas interessantes sobre as experiências de discriminação. Essas indicações podem ser a profundadas a partir de estudos subseqüentes sobre as ações dos projetos, ampliando assim o entendimento dos circuitos, das redes e dos processos que envolvem as prátic as discrimina tórias em face das especific idades das relações racia is no Rio de Janeiro e no Brasil.

\section{Referências bibliográficas}

ADORNO, Sérgio. "Violência e racismo: discriminação no acesso à justiça penal". In: SCHWARCZ, Lílian Moritz; QUEIROZ, Renato da Silva (Orgs.). Raça e diversidade. São Paulo: EDUSP/Estação Ciência, 1996. p. 255-275.

CANO, Inácio; FERREIRA, Carlos Eugênio. "Homicídios e evolução demográfica no Brasil: impacto da evolução demográfica na futura taxa de homicídiose a incidência dos homicídios na pirâmide populacional". In: HASENBALG, Carlos; SILVA, Nelson do Valle (Orgs.). Origens e destinos: desigualda des socia is a o longo da vida. Rio de Janeiro: Topboobks Editora, 2003. p. 281358

CASTEL, Robert. Metamorphoses de la question sociale. Paris: Fayard, 1995.

CASTRO, Mary Garcia; ABRAMOVAY, Miria m; RUA, Ma ria das Graças. Cultivando vida, desarmando violências: experiências em educação, cultura, lazer, esporte e cidadania com jovens em situação de pobreza. Brasília: UNESCO, Brasil Telecom, Fundação Kellog e Banco Interamericano de Desenvolvimento, 2001. 
CECCHETTO, Fátima. Violência e estilos de masculinidade. Rio de Janeiro: Editora FGV, 2004.

CRENSHAW, Kimberlé. "Doc umento para o encontro de especialistas em a spectos da discriminação racial relativos a o gênero". Revista Estudos Feministas, v. 10, n. 1, p. 171-188, 2002.

FGV - FUNDAÇÃO GETÚLIO VARGAS. Dicionário de Ciências Socia is. Coordenação de Benedito Silva. Rio de J a neiro: FGV, 1986.

FREYRE, Gilberto. Casa Grande \& Senzala: formação da fa mília brasileira sob o regime da economia patriarcal. Rio de Janeiro: José Olympio, 1984.

FRY, Peter. "Politic a mente correto num lugar, inc orreto noutro? Relações racia is no Brasil, nos Estados Unidos, em Moçambique e no Zmbábue". Estudos Afro-Asiáticos, v. 21, p. 167-177, dez. 1991.

. "Politics, Nationality, and the Meaning of 'Race' in

Brazil." Daedalus: J ournal of the American Academy of Arts and Sciences, v. 129, p. 83-118, 2000.

GRIN, Mônica. "Políticas públicas e desigualdade racial: do dilema à ação". In: MONTEIRO, Simome; SANSONE, Ĺvio (Orgs.). Etnicidade na Améric a Latina: um debate sobre raça, saúde e direitos reprodutivos. Rio de J aneiro: Editora Fiocruz, 2004. p. 331-344.

GUIMARÃES, Antônio Sérgio. "Racismo e restrição de direitos ind ividua is: a discrimina ção racial 'public izada'". Estudos Afro-Asiátic os, Rio de Janeiro, v. 34, p. 51-78, 1997.

Racismo e anti-racismo no Brasil. São Paulo: Ed. 34, 1999.

HASENBALG, Carlos. "Entre o mito e os fatos: racismo e relações racia is no Brasil". In: MAIO, Marcos Chor; SANTOS, Ricardo Ventura (Orgs.). Raça, ciência e sociedade. Rio de J aneiro: Fiocruz, 1996. p. 235-249.

HASENBALG, Carlos; SILVA, Nelson do Valle. "Notas sobre desigualdade racial e política no Brasil". Estudos AfroAsiátic 0s, v. 25, p. 141-159, 1993.

HERINGER, Rosane. "Mapeamento das ações e discursos de comba te às desigualda des racia is no Brasil". Estudos Afro-Asiátic os, v. 23, n. 2, p. 291-334, 2001.

HTUN, Mala. "From 'Racial Democracy' to Affirmative Action: Changing State Policy on Race in Brazil". Latin Americ an Research Review, v. 39, n. 1, p. 60-89, 2004.

MAGGIE, Yvonne. "Aqueles a quem foi negada a luz do dia: as categorias de cor e raça na cultura brasileira". In: MAIO, Marc os C hor; SANTOS, Ric a rdo Ventura (Orgs.). Raça, ciência e sociedade. Rio de Janeiro: Fiocruz, 1996. p. 225-234.

MAIO, Marcos Chor. A história do Projeto UNESC O: estudos racia is e ciências soc ia is no Brasil. 1997. Tese (Doutora do 
em Ciência Política) - Universidade Cândido Mendes/ IUPERJ , Rio de J a neiro.

. "O Projeto UNESCO e a agenda das ciências socia is dosanos 40 e 50". Revista Bra sileira de Ciências Socia is, São Paulo, v. 14, n. 41, p. 141-158, 1999.

MAIO, Marcor Shor; MONTEIRO, Simone. "Tempo de racialização: o caso da saúde da 'população negra' no Brasil". História, Ciências, Saúde - Manguinhos, v. 12, n. 2, p. 419-446, maio/ago. 2005.

MINAYO, Maria Cecília S. "Violência social sob a perspectiva da saúde pública". Cadernos de Saúde Pública, v. 10, suplemento 1, p. 7-8, 1994.

MONTEIRO, Simone. Qual prevenção? Aids, sexualidade e gênero em um favela carioca. Rio de Janeiro: Editora Fiocruz, 2002.

"Desigualdades em saúde, raça e etnicidade: questões e desafios". In: MONTEIRO, Simone; SANSONE, Lívio (Orgs.). Etnicidade na América Latina: um debate sobre raça, saúde e direitos reprodutivos. Rio de J aneiro: Editora Fiocruz, 2004. p. 45-56.

MONTEIRO, Simone; CECCHETTO, Fátima. "Trajetórias juvenis e intervenções socia is: repercussões nas práticas socia is e em saúde (RJ, Brasil)". Cadernos de Saúde Pública, Rio de Janeiro, v. 22, n. 1, p. 193-200, jan. 2006.

MUNANGA, Ka bengele. "As fac etas do rac ismo silencia do". In: SCHWARCZ, Lílian Moritz; QUEIROZ, Renato da Silva (Orgs). Raça e diversidade. São Paulo: EDUSP/Estação Ciência, 1996. p. 213-229.

NOGUEIRA, Oracy. Preconceito de marca: as relações racia is em Itapetininga. São Paulo: Editora da USP,1998.

NOVAES, Regina R. "Juventudes cariocas: mediações, conflitos e encontros cultura is". In: VIANNA, Hermano (Org.). Galeras cariocas: territórios de conflitos e encontros culturais. Rio de Janeiro: Editora da UFRJ, 1997. p. 119-160.

NOVAES, Regina; MAFRA, Clara. "yuventude, conflito social e solidariedade". Comunic ações do ISER, v. 50, n. 17, p. 143-158, 1998.

OLVEIRA, Luiz Pereira Cloves; BARRETO, Paula Cristina da Silva. "Percepção do rac ismo no Rio de J a neiro". Estudos Afro-Asiátic os, ano 25, n. 2, p. 183-213, 2003.

RAMOS, Sívia; MUSUMECI, Leonarda. Elemento suspeito: abordagem policial e discriminação no Rio de J aneiro. Rio de Ja neiro: Civilizaçã o Bra sileira, 2005.

SANSONE, Lívio. Negritude sem etnicidade: o local e o global nas relações raciais e na produção cultural negra do Brasil. Salvador: EDUFBA/Pallas, 2003 [1993]. 
SCHWARCZ, Ĺlian Moritz. "As teorias rac ia is, uma construção histórica de finais do século XIX: o contexto brasileiro". In: SCHWARCZ, Ĺlian Moritz; QUEIROZ, Renato da Silva (Orgs.). Raça e diversidade. São Paulo: EDUSP/Estação Ciência, 1996. p. 147-185.

SOARES, Luiz Eduardo et al. Violência e política no Rio de J aneiro. Rio de J a neiro: Relume Dumará/ISER, 1996.

STOLKE, Verena. "Sexo está para gênero assim como raça para etnicidade?" Estudos Afro-Asiátic os, v. 20, p. 101119, jun. 1991.

TURRA, Cleusa; VENTURI, Gusta vo (Orgs.). Racismo cordial: a mais completa análise sobre o preconceito de cor no Brasil. São Paulo: Ática, 1995.

ZALUAR, Alba. "Violência, dinheiro fácil e justiça no Brasil: 1980-1995". Estudos Afro-Asiáticos, v. 34, p. 7-33, maio 1999.

. Integração perversa: pobreza e tráfico de drogas. Rio de Janeiro: Editora FGV, 2004.

[Recebido em outubro de 2005 e aceito para publicação em abril de 2006]

Discrimination, Color and Social Intervention Among Youth: The Male Perspective (R), Brazil) Abstract: This work a pproaches the thematic of disc rimination and racism among carioca youth, through the analysis of the insights, experiences and reactions of the group before prejudicial situations. The study integrates a broader research a bout the effects of social interventions in the trajectories of young males and females from the popular layers. Hence, meaningful interviews have been made with 42 youths aged 18 through 24 , with and without the participation in projects concerned with the citizenship and professional capacitation. Herein we have privileged the analysis of the youths' talks about the circuits, the networks and the processes that involve the discriminatory prac tic es in Rio de $J$ aneiro city. We empha size the configurations that discrimination and racism assume among young males with experience in social projects and their implic ation for the sociability and access to certain social spaces. The comparative perspective among youths with and without institutional experience has given interesting insights on race, class and gender, thus broadening the understanding of the racial relations specificities in Brazil.

Key Words: Disc rimination, youth, social intervention, racial relations, gender, masc ulinity. 